\title{
Ginkgo biloba: a natural reducing agent for the synthesis of cytocompatible graphene
}

\author{
This article was published in the following Dove Press journal: \\ International Journal of Nanomedicine \\ 7 January 2014 \\ Number of times this article has been viewed
}

\section{Sangiliyandi Gurunathan Jae Woong Han Jung Hyun Park Vasuki Eppakayala Jin-Hoi Kim}

Department of Animal Biotechnology, Konkuk University, Seoul, South Korea

Correspondence: Sangiliyandi Gurunathan; Jin-Hoi Kim

Department of Animal Biotechnology, Konkuk University, I Hwayang-dong, Gwangin-gu, Seoul I43-70I, South Korea Email gsangiliyandi@yahoo.com; jhkim54I@konkuk.ac.kr
Background: Graphene is a novel two-dimensional planar nanocomposite material consisting of rings of carbon atoms with a hexagonal lattice structure. Graphene exhibits unique physical, chemical, mechanical, electrical, elasticity, and cytocompatible properties that lead to many potential biomedical applications. Nevertheless, the water-insoluble property of graphene restricts its application in various aspects of biomedical fields. Therefore, the objective of this work was to find a novel biological approach for an efficient method to synthesize water-soluble and cytocompatible graphene using Ginkgo biloba extract (GbE) as a reducing and stabilizing agent. In addition, we investigated the biocompatibility effects of graphene in MDA-MB-231 human breast cancer cells.

Materials and methods: Synthesized graphene oxide (GO) and GbE-reduced GO (Gb-rGO) were characterized using various sequences of techniques: ultraviolet-visible (UV-vis) spectroscopy, Fourier-transform infrared spectroscopy (FTIR), dynamic light scattering (DLS), scanning electron microscopy (SEM), atomic force microscopy (AFM), and Raman spectroscopy. Biocompatibility of GO and Gb-rGO was assessed in human breast cancer cells using a series of assays, including cell viability, apoptosis, and alkaline phosphatase (ALP) activity.

Results: The successful synthesis of graphene was confirmed by UV-vis spectroscopy and FTIR. DLS analysis was performed to determine the average size of GO and Gb-rGO. X-ray diffraction studies confirmed the crystalline nature of graphene. SEM was used to investigate the surface morphologies of GO and Gb-rGO. AFM was employed to investigate the morphologies of prepared graphene and the height profile of GO and Gb-rGO. The formation of defects in Gb-rGO was confirmed by Raman spectroscopy. The biocompatibility of the prepared GO and Gb-rGO was investigated using a water-soluble tetrazolium 8 assay on human breast cancer cells. GO exhibited a dose-dependent toxicity, whereas Gb-rGO-treated cells showed significant biocompatibility and increased ALP activity compared to GO.

Conclusion: In this work, a nontoxic natural reducing agent of $\mathrm{GbE}$ was used to prepare soluble graphene. The as-prepared Gb-rGO showed significant biocompatibility with human cancer cells. This simple, cost-effective, and green procedure offers an alternative route for large-scale production of rGO, and could be used for various biomedical applications, such as tissue engineering, drug delivery, biosensing, and molecular imaging.

Keywords: alkaline phosphatase activity, atomic force microscopy, biocompatibility, cell viability, graphene, Fourier-transform infrared spectroscopy, scanning electron microscopy, Raman spectroscopy, UV-visible spectroscopy

\section{Introduction}

Graphene is a single-atom-thick, two-dimensional sheet of hexagonally arranged carbon atoms isolated from its three-dimensional parent material - graphite (Gt). ${ }^{1}$ 
Graphene exhibits attractive electronic, catalytic, mechanical, optical, and magnetic properties. These properties provide graphene with great potential in various applications ranging from energy storage to biomedical materials. ${ }^{2}$ Due to its remarkable physical, chemical, and mechanical properties and with a view to important applications, graphene has been emerging as one of the areas of research attracting great interest in academia and industry. ${ }^{3-5}$ Recently, graphene has attracted much attention in the scientific community for its numerous potential applications in biotechnology, including biosensing, ${ }^{6,7}$ disease diagnostics,${ }^{8}$ antibacterial ${ }^{9-11}$ and antiviral materials, ${ }^{12}$ cancer targeting, ${ }^{13}$ photothermal therapy, ${ }^{14}$ drug delivery, ${ }^{15}$ and tissue engineering. ${ }^{16,17}$

Regarding biomedical applications of graphene materials, Lee et $\mathrm{al}^{18}$ suggested that graphene and graphene oxide (GO) sheets can be used as biocompatible, transferable, and implantable platforms for stem cell culture. Further, Lee et $\mathrm{al}^{18}$ reported that the noncovalent binding capability of graphene allows it to act as a preconcentration platform for osteogenic inducers, which accelerate mesenchymal stem cells growing on it toward the osteogenic lineage. Nayak et $\mathrm{al}^{19}$ reported that graphene-treated human mesenchymal stem cells show enhanced proliferation and differentiation. Chen et $\mathrm{al}^{20}$ reported that graphene and GO can support induced pluripotent stem cell culture and allow for spontaneous differentiation, and also suggested that the different surface properties of graphene and GO influence the performance of induced pluripotent stem cell culture and applications. The different physical and chemical properties could influence the biological responses of cells. Bacillus marisflavi-reduced GO exhibited toxicity to MCF-7 cells in a dose-dependent manner. ${ }^{21}$ Graphene-family nanomaterials can be either benevolent or toxic to cells, and biological response depends on layer number, lateral size, stiffness, hydrophobicity, surface functionalization, and dose. ${ }^{22}$

The success of graphene synthesis depends on safe and nontoxic methods, and large-scale production at low cost. ${ }^{23}$ In this regard, the approach that first led to the isolation of graphene using micromechanical cleavage method was a low-yield, low-throughput process, and therefore not likely to be industrially scalable. ${ }^{1}$ Simultaneously, several other research groups have developed various approaches for the synthesis of graphene and its derivatives, including exfoliation of $\mathrm{Gt},{ }^{24,25}$ flash reduction, ${ }^{26}$ hydrothermal dehydration, ${ }^{27}$ mechanical exfoliation, ${ }^{28}$ epitaxial growth, ${ }^{29}$ photocatalysis, ${ }^{30}$ and photodegradation. ${ }^{31}$ Graphene material has been produced physically, chemically, and mechanically for a long time, but recent developments have shown the critical role of microorganisms and biological reducing agents for the production of graphene. The use of biological systems in this area is rapidly developing due to their ease of handling, availability, and nontoxicity. Moreover, biological synthesis of graphene is an environmentally friendly method without the use of harsh, toxic, and expensive chemicals.

Generally, the most common synthesis of graphene has utilized chemical reducing agents, such as hydrazine, sodium citrate, and sodium borohydride to reduce $\mathrm{GO},{ }^{24,25}$ which can lead to the absorption of harsh chemicals on the surfaces of nanoparticles, raising the toxicity issue. Currently, the green synthesis of graphene is being investigated to decrease the use of toxic chemicals and increase biocompatibility in biotechnology and biomedical applications. For the development of green chemistry, several biological materials, such as wild carrot root, ${ }^{32}$ yeast, ${ }^{33}$ Escherichia coli, ${ }^{34,35}$ E. fergusoni, ${ }^{36}$ Pseudomonas aeruginosa, ${ }^{37}$ and the humanin peptide, ${ }^{38}$ have been reported as serving as both reducing and stabilizing agents for green synthesis of graphene. The organisms used in graphene synthesis vary from simple prokaryotic systems to complex eukaryotes. The biological synthesis of nanomaterials using plants has received more attention as a suitable alternative to chemical procedures and physical methods. ${ }^{39}$ Extracts from plants may act both as reducing and capping agents in nanoparticle synthesis. ${ }^{40,41}$ In general, plants contain many biomolecules, such as proteins, amino acids, polysaccharides, alkaloids, alcoholic compounds, polyphenols, enzymes, chelating agents, and vitamins. These molecules play an important role in the bioreduction, formation, and stabilization of metal nanoparticles. ${ }^{40,41}$ Therefore, plant extracts could be used as an alternative reducing and stabilizing agent for the synthesis of graphene. In general, extracts of Ginkgo biloba leaves, which contain flavonoid, glycosides, and terpenoids, have been used pharmaceutically in the People's Republic of China, South Korea, and Japan, due to their nootropic properties. Here, we explored the possibility of using G. biloba leaf extract as an alternative reducing agent for the synthesis of graphene, and also evaluated the biocompatibility effect of as-prepared graphene in human breast cancer cells.

\section{Materials and methods}

Gt powder was purchased from Sigma-Aldrich (St Louis, MO, USA). $\mathrm{NaOH}, \mathrm{KMnO}_{4}, \mathrm{NaNO}_{3}$, anhydrous ethanol, $98 \%$ $\mathrm{H}_{2} \mathrm{SO}_{4}, 36 \% \mathrm{HCl}$, and $30 \%$ hydrogen peroxide $\left(\mathrm{H}_{2} \mathrm{O}_{2}\right)$ aqueous solution were purchased from Sigma-Aldrich and used directly without further purification. All aqueous solutions were prepared with deionized water. All other chemicals were purchased from Sigma-Aldrich unless stated otherwise. 


\section{Synthesis of graphene oxide}

The synthesis of GO was performed as described previously. ${ }^{37,38,42}$ Briefly, Gt powder was oxidized to Gt oxide (GtO) using $\mathrm{KMnO}_{4} / \mathrm{H}_{2} \mathrm{SO}_{4}$, and then the $\mathrm{GtO}$ was exfoliated into GO sheets by ultrasonication in water. In a typical synthesis process, natural Gt powder $(2 \mathrm{~g})$ was added to cooled $\left(0^{\circ} \mathrm{C}\right) \mathrm{H}_{2} \mathrm{SO}_{4}(350 \mathrm{~mL} \mathrm{v} / \mathrm{v})$, and then $\mathrm{KMnO}_{4}(8 \mathrm{~g} \mathrm{w} / \mathrm{v})$ and $\mathrm{NaNO}_{3}(1 \mathrm{~g} \mathrm{w} / \mathrm{v})$ were added gradually while stirring. The mixture was transferred to a $40^{\circ} \mathrm{C}$ water bath and stirred for 60 minutes. Deionized water $(250 \mathrm{~mL})$ was slowly added, and the temperature was increased to $98^{\circ} \mathrm{C}$. The mixture was maintained at $98^{\circ} \mathrm{C}$ for a further 30 minutes, and the reaction was terminated by the addition of deionized water $\left(500 \mathrm{~mL}\right.$ ) and $40 \mathrm{~mL}$ of $30 \% \mathrm{H}_{2} \mathrm{O}_{2}$ solution (v/v). The color of the mixture changed to brilliant yellow, indicating the oxidation of pristine Gt to GtO. The mixture was then filtered and washed with diluted $\mathrm{HCl}$ to remove metal ions. Finally, the product was washed repeatedly with distilled water until pH 7.0 was achieved. The sample of GtO was obtained after drying. To prepare GO, the synthesized GtO was redispersed in distilled water to create a yellow-brown dispersion, and the exfoliation of GtO to generate GO sheets was achieved by ultrasonication for 30 minutes. The resulting aqueous dispersion of the brown GO sheet was stable.

\section{Preparation of leaf extract}

Fresh G. biloba leaves were collected from Konkuk University campus and stored at $4^{\circ} \mathrm{C}$ until needed. Twenty grams of $G$. biloba leaves were washed thoroughly with double-distilled water, and were then sliced with a sharp stainless steel knife into fine pieces, about $1-5 \mathrm{~cm}^{2}$. The finely cut $G$. biloba leaves were mixed in $100 \mathrm{~mL}$ of sterile distilled water and then boiled for 5 minutes. After boiling, the mixture was filtered through Whatman grade 1 filter paper. The extract was used for synthesis of graphene. The extract was stored at $4{ }^{\circ} \mathrm{C}$ until further use.

\section{Reduction of graphene oxide by GbE}

The reduction of GO was performed as described previously. ${ }^{38}$ Briefly, reduced GO was obtained from the reaction of a plant extract with GO. In the typical reduction experiment, $10 \mathrm{~mL}$ of G. biloba extract (GbE) was added to $90 \mathrm{~mL}$ of $0.5 \mathrm{mg} / \mathrm{mL}$ aqueous GO solution, and then the mixture was kept in a tightly sealed glass bottle and stirred at $30^{\circ} \mathrm{C}$ for 12 and 24 hours. Then, by using a magneto-stirrer heater, reduced GO suspension was stirred at $400 \mathrm{rpm}$ at a temperature of $30^{\circ} \mathrm{C}$ for 30 minutes. A homogeneous GbE-reduced GO (Gb-rGO) suspension was obtained without aggregation.
Then, functionalized Gb-rGO was filtered and washed with deionized water. Finally, a black Gb-rGO dispersion was obtained.

\section{Characterization}

Ultraviolet-visible (UV-vis) spectra were obtained using a WPA Biowave II (Biochrom, Cambridge, UK). The aqueous suspension of GO and Gb-rGO was used as the UV-vis samples, and the deionized water was used as the reference. The particle size of dispersions was measured by a Zetasizer Nano ZS90 (Malvern Instruments, Malvern, UK). X-ray diffraction (XRD) analyses were carried out on an X-ray diffractometer (D8 Discover; Bruker AXS, Madison, WI, USA). The high-resolution XRD patterns were measured at $3 \mathrm{Kw}$ with $\mathrm{Cu}$ target using a scintillation counter; $\lambda=1.5406 \AA$ at $40 \mathrm{kV}$ and $40 \mathrm{~mA}$ was recorded in the range of $2 \theta=5^{\circ}-80^{\circ}$. The dried powder was diluted with potassium bromide in a ratio of 1:100, and Fourier-transform infrared spectroscopy (FTIR) and spectrum GX spectrometry within the range of 500-4,000 $\mathrm{cm}^{-1}$ were recorded. A JSM-6700F (JEOL, Tokyo, Japan) semi-in-lens field-emission scanning electron microscope (SEM) operating at $10 \mathrm{kV}$ was used to acquire SEM images. The solid samples were transferred to a carbon tape held in an SEM sample holder for analyses. The analyses of the samples were carried out at an average working distance of $6 \mathrm{~mm}$. Raman spectra of GO and reduced GO were measured by an Alpha300 (Witec, Ulm, Germany) with a $532 \mathrm{~nm}$ laser. The calibration was initially made using an internal silicon reference at $500 \mathrm{~cm}^{-1}$, and gave a peak position resolution of less than $1 \mathrm{~cm}^{-1}$. The spectra were measured from 500 to $4,500 \mathrm{~cm}^{-1}$. All samples were deposited on glass slides in powder form without using any solvent. Surface images were measured using tapping-mode atomic force microscopy (AFM) (SPA 400; Seiko Instruments, Chiba, Japan) operating at room temperature. Height and phase images were recorded simultaneously using nanoprobe cantilevers (SI-DF20; Seiko Instruments).

\section{Cell culture and exposure to $\mathrm{GO}$ and Gb-rGO}

MDA-MB-231 human breast cancer cells were kindly provided by Professor Kyung Jin Lee, Department of Medicine, University of Ulsan College of Medicine, Asan Medical Center, Seoul. MDA-MB-231 breast cancer cell lines were grown adherently and maintained in Dulbecco's Modified Eagle's Medium (DMEM) containing 10\% fetal bovine serum (FBS), $50 \mathrm{U} / \mathrm{mL}$ penicillin, and $50 \mathrm{mg} / \mathrm{ml}$ streptomycin in a humidified atmosphere containing $5 \% \mathrm{CO}_{2}$ at $37^{\circ} \mathrm{C}$. All 
experiments were performed in six-well plates, unless stated otherwise. Cells were seeded onto the plates at a density of $1 \times 10^{4}$ cells per well and incubated for 24 hours prior to the experiments. The cells were washed with phosphate-buffered saline (PBS; $\mathrm{pH} 7.4$ ) and incubated in fresh medium containing different concentrations of GO and Gb-rGO dissolved in water. GO or Gb-rGO suspensions were freshly prepared before the cells were exposed, and diluted to appropriate concentrations from 10 to $100 \mu \mathrm{g} / \mathrm{mL}^{-1}$ with the culture medium, then immediately applied to the cells. Cells not treated with GO or Gb-rGO served as controls in each experiment.

\section{Cell-viability assay}

A water-soluble tetrazolium (WST)-8 assay was performed as described previously in Liao et al. ${ }^{43}$ Typically, $1 \times 10^{4}$ cells were seeded in a 96-well plate and cultured in DMEM supplemented with $10 \% \mathrm{FBS}$ at $37^{\circ} \mathrm{C}$ under $5 \% \mathrm{CO}_{2}$. After 24 hours, the cells were washed twice with $100 \mu \mathrm{L}$ of serumfree DMEM and further incubated with $100 \mu \mathrm{L}$ of different concentrations of GO or Gb-rGO suspensions in serum-free DMEM. After 24 hours' exposure, the cells were washed twice with serum-free DMEM, and $15 \mu \mathrm{L}$ of WST-8 solution was added to each well containing $100 \mu \mathrm{L}$ of serum-free DMEM. After 1 hour's incubation at $37^{\circ} \mathrm{C}$ under $5 \% \mathrm{CO}_{2}$, $80 \mu \mathrm{L}$ of the mixture was transferred to another 96 -well plate, because residual GO or Gb-rGO can affect the absorbance values at $450 \mathrm{~nm}$. The absorbance of the mixture solutions was measured at $450 \mathrm{~nm}$ using a microplate reader. The cellfree control experiments were performed to see if the GO and Gb-rGO reacted directly with the WST- 8 reagents. Typically, $100 \mu \mathrm{L}$ of GO or Gb-rGO suspensions with different concentrations $(10-100 \mu \mathrm{g} / \mathrm{mL})$ were added to a 96-well plate and $10 \mu \mathrm{L}$ of WST-8 reagent solution was added to each well; the mixture solution was incubated at $37^{\circ} \mathrm{C}$ under $5 \% \mathrm{CO}_{2}$ for 1 hour. After incubation, the GO or Gb-rGO was centrifuged, and $50 \mu \mathrm{L}$ of supernatant was transferred to another 96-well plate. Optical density was measured at $450 \mathrm{~nm}$.

\section{TUNEL assay}

Cell morphology and apoptosis were evaluated by fluorescence microscopy following 4',6-diamidino-2-phenylindole (DAPI) staining. MDA-MB-231 human breast cancer cells were grown in six-well plates and treated with $100 \mu \mathrm{g} / \mathrm{mL}$ of GO or Gb-rGO for 24 hours, then the cells were harvested with trypsin, washed with PBS, and fixed with 4\% paraformaldehyde in PBS for 10 minutes at room temperature. Fixed cells were washed with PBS and stained with DAPI final concentration $0.5 \mu \mathrm{g} / \mathrm{mL}$ for 10 minutes at room temperature. The cells were washed three times with PBS, and images were captured using a fluorescence microscope. Apoptotic cells were identified by features characteristic of apoptosis. The tests were performed in triplicate.

Apoptotic deoxyribonucleic acid (DNA) fragmentation was also detected by using a DNA-fragmentation imaging kit (Roche, Basel, Switzerland) following the manufacturer's instructions. Based on the terminal deoxynucleotidyl transferase-mediated deoxyuridine triphosphate nick-end labeling (TUNEL) reaction, apoptosis assay was performed, fluorescence detection of cells with apoptotic DNA strand breaks was performed. To examine total cell numbers, nuclei were labeled simultaneously with DAPI. Merged images of both channels were shown using a fluorescence microscope (Olympus, Tokyo, Japan) at 100× magnification.

\section{Alkaline phosphatase activity}

MDA-MB-231 human breast cancer cells were cultured in 48 -well culture dishes at a density of $5 \times 10^{3}$ cells per well and cultured for 5 days. Then, medium was replaced with treatment medium, which was DMEM containing 5\% serum plus GO or Gb-rGO. After 5 days, the alkaline phosphatase (ALP) activity was measured according to the method described by the manufacturer's instructions (QuantiChrom ${ }^{\mathrm{TM}}$ DALP-250 alkaline phosphatase assay kit; Gentaur, Aachen, Germany). The amount of released $p$-nitrophenol was measured at $405 \mathrm{~nm}$ in a 96-well microplate reader. Enzyme activity was evaluated as the amount of nitrophenol released through the enzymatic reaction, and absorbance was recorded using a microplate reader (model 680; Bio-Rad Laboratories, Hercules, CA, USA) at $405 \mathrm{~nm}$. For normalization, the total protein content was measured using a bicinchoninic acid protein assay kit (Thermo Fisher Scientific, Waltham, MA, USA). Thus, the ALP activity was expressed and normalized by the total protein content (U/mg).

\section{Results and discussion Characterization of GO and Gb-rGO}

Figure 1 shows the reduction of GO before and after treatment with the leaf extract of G. biloba. Briefly, the Gt powder was first oxidized into $\mathrm{GtO}$ using $\mathrm{KMnO}_{4} / \mathrm{H}_{2} \mathrm{SO}_{4}$, and then the $\mathrm{GtO}$ was exfoliated into $\mathrm{GO}$ sheets by ultrasonication in water. ${ }^{37,38,42}$ In a typical reduction experiment, $10 \mathrm{~mL}$ of $\mathrm{GbE}$ was added to the $90 \mathrm{~mL}$ of $\mathrm{GO}$ dispersion $(0.5 \mathrm{mg} / \mathrm{mL})$, and the mixture was stirred at $37^{\circ} \mathrm{C}$ for 24 hours. As shown in Figure 1, after reduction, a homogeneous yellow-brown GO dispersion was converted to black, which indicates the transition of GO to graphene. The color of GO and Gb-rGO 
A

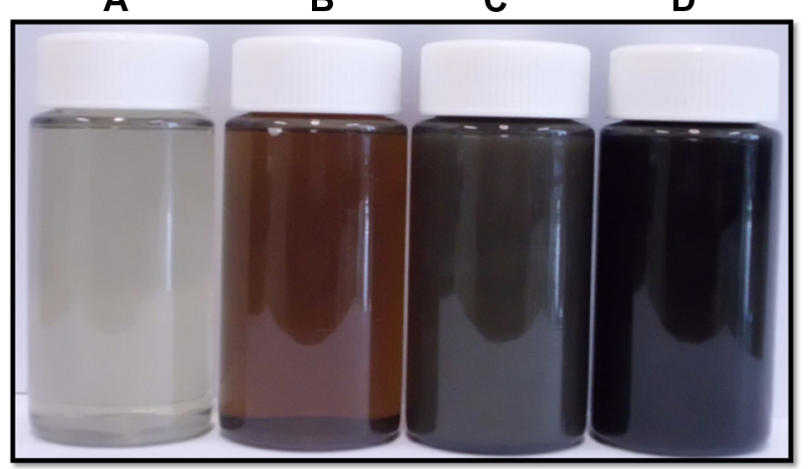

Figure I Digital photographs of aqueous dispersions of Ginkgo biloba (Gb) extracts $(0.5 \mathrm{mg} / \mathrm{mL})(\mathbf{A})$ of graphene oxide (GO) before (B) and after 12 hours (C) and 24 hours (D) reduction of $\mathrm{GO}$ using $\mathrm{Gb}$ extract.

appear different because of their distinct structural and physicochemical properties. ${ }^{44}$ The reduction of GO is also indicated from the color change of the solution before and after reaction (from yellow brown to dark), which could serve as a piece of evidence for the conversion of GO to graphene and also is due to the large number of hydrophilic functional groups, such as carboxyl, hydroxyl, and epoxy groups, on GO nanosheets. ${ }^{44}$ Further, the reduction of GO was investigated by UV-vis spectroscopy, as shown in Figure 2. GO and Gb-rGO samples were analyzed. GO exhibited peaks at $230 \mathrm{~nm}$ attributed to $\pi-\pi^{*}$ transitions of aromatic $\mathrm{C}=\mathrm{C}$ bonds and a shoulder at about $300 \mathrm{~nm}$ (ascribed to $\pi-\pi^{*}$ transition of $\mathrm{C}=\mathrm{O}$ bonds). Upon $\mathrm{GO}$ incubation with $\mathrm{GbE}$, after stirring for 12 hours at $37^{\circ} \mathrm{C}$, the absorption of $\mathrm{C}=\mathrm{C}$ bonds at $230 \mathrm{~nm}$ was red-shifted to $260 \mathrm{~nm}$. With increased time to 24 hours, the absorption of $\mathrm{C}=\mathrm{C}$ bonds slightly shifted to $270 \mathrm{~nm}$, and also the absorption value increased when compared to 12-hour reduction (Figure 2), indicating that the reduction of GO had been completed in 24 hours. We also observed that the reduction was completed within 24 hours, because the peak shifted no more when the reaction time was extended. The disappearance of the peak at $230 \mathrm{~nm}$ and the appearance of a new peak around $270 \mathrm{~nm}$ emerged in the UV spectra of the Gb-rGO, suggesting that $s p^{2}$ carbon was restored and atoms were possibly rearranged within Gb-rGO. ${ }^{39,45}$

Fernández-Merino et $\mathrm{al}^{23}$ suggested that the maximum red-shift value can be used as a yardstick to estimate the performance of the reducing agent. In this regard, Gb-rGO showed a similar final absorption peak position to the hydrazine, ${ }^{46}$ tea polyphenol-reduced graphene, ${ }^{45}$ and phenylhydrazine-reduced graphene. ${ }^{47}$ The results implied that GO could be reduced and the aromatic structure could be restored using $\mathrm{GbE}$ as a reducing agents. The data obtained from our studies consistent with previous reports used various reducing agents to reduce $\mathrm{GO}$, such as vitamin $\mathrm{C},{ }^{23}$ thiourea, ${ }^{48}$ and leaf extracts of Colocasia esculenta and Mesua ferrea. ${ }^{39}$ Therefore, the reduction of GO with plant extract was not only a simple but also safe and environmentally friendly approach. It is a potent green manufacturing technology to produce graphene in large quantities.

\section{XRD analysis of GO and Gb-rGO}

To estimate the distance between two layers is an important parameter for the structural information of the graphene. ${ }^{49}$

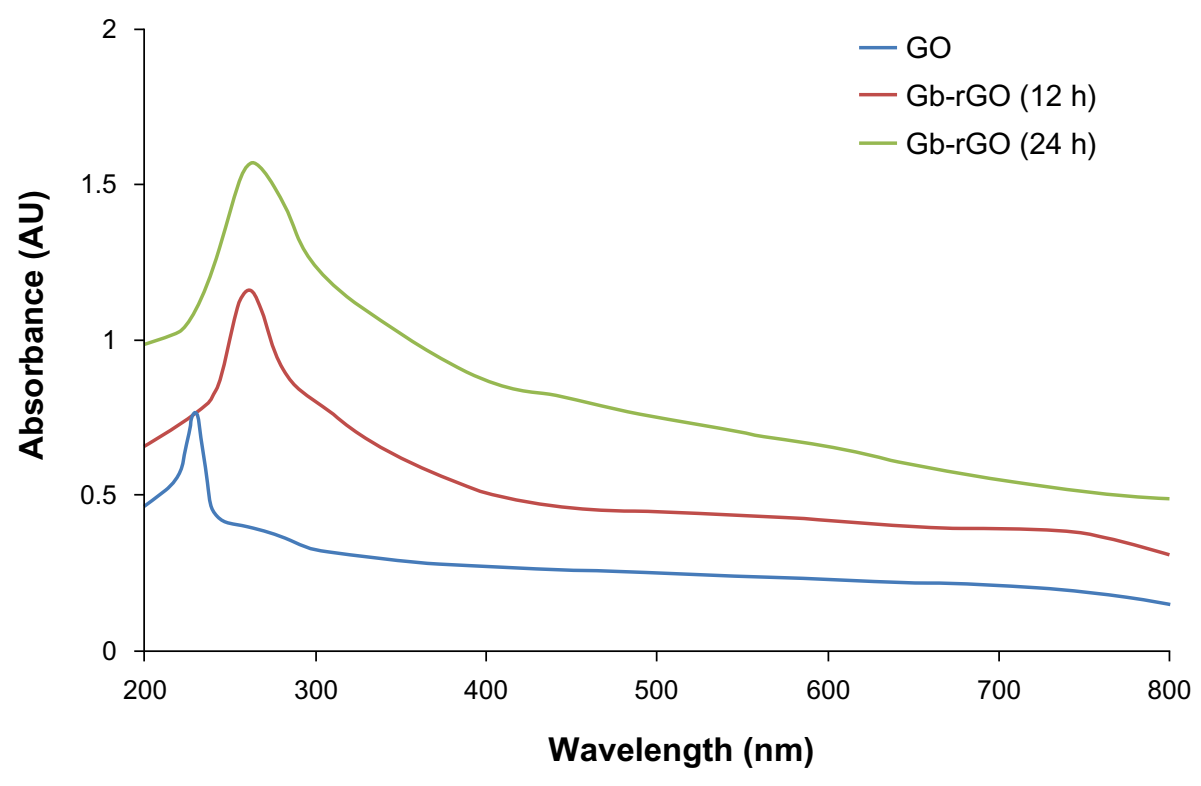

Figure 2 Ultraviolet-visible absorption spectra of graphene oxide (GO) and Ginkgo biloba extract-reduced GO (Gb-rGO) suspension in water. Abbreviations: AU, arbitrary unit; h, hours. 
The crystalline structure of the GO and Gb-rGO was further studied using XRD. The XRD pattern of GO exhibits a characteristic peak at $11.7^{\circ}$ (Figure $3 \mathrm{~A}$ ), whereas, Gb-rGO shows a peak at $26.4^{\circ}$ which is close to that of pure rGO. ${ }^{50}$ As shown in Figure $3 \mathrm{~A}$, the XRD pattern of exfoliated GO shows a peak at $2 \theta=11.7^{\circ}$, corresponding to an interlayer with a $d$-spacing of $7.6 \AA$, indicating the presence of oxygen functional groups, which facilitate hydration and exfoliation of graphene sheets in the aqueous media. Upon oxidation of pristine Gt, the (002) peak shifts to the lower angle at $2 \theta=11.7^{\circ}$. This indicates that the distance between the graphene sheets has increased due to the presence of oxygen-containing functional groups attached on both sides of the graphene sheet and the atomicscale roughness arising from structural defects ( $s p^{3}$ bonding) generated on the originally atomically flat graphene sheet, ${ }^{37,51}$ the $d$-spacing of the $\mathrm{GO}$ is about $0.76 \mathrm{~nm}\left(2 \theta \approx 11.7^{\circ}\right)$, which is significantly larger than the $d(002)$ value of Gt $d$ of around $0.34 \mathrm{~nm}\left(2 \theta \approx 26.2^{\circ}\right)$-thickness single-layer pristine graphene. ${ }^{37,49}$ In contrast to $\mathrm{GO}, \mathrm{Gb}-\mathrm{rGO}$ has a broad peak centered at $2 \theta=26.4^{\circ}$, corresponding to $d$-spacing of $0.34 \mathrm{~nm}$, which may be due to restacking of graphene layers (Figure 3B). The close $d$-spacing of Gb-rGO to pristine $\mathrm{Gt}$ and disappearance of the peak at $2 \theta=11.7^{\circ}$ indicates that the oxygen-containing group of GO has been efficiently removed.
This shift in the interlayer spacing can be attributed to the reduction of the $\mathrm{GO}$, where the reduction leads $\mathrm{rGO}$ to pack more tightly than the GO. ${ }^{37,52}$ Though there is a decrease in the interlayer spacing compared with GO, the basal spacing of rGO is higher than that of well-ordered Gt. The higher basal spacing may be due to the presence of residual oxygen functional groups, indicating incomplete reduction of GO. ${ }^{49}$ The large interlayer distance has been attributed to the formation of hydroxyl, epoxy, and carboxyl groups. Due to the removal of various functional groups in the process of significant reduction of $\mathrm{GO}$ using $\mathrm{GbE}$ as a reducing agent, the interlayer distance was diminished, the peak of the large interlayer distance disappeared completely, and a broad peak near $3.4 \AA$ became visible (Figure 3B). This suggested that most of the functional groups were removed, and the reduction was significant.

\section{FTIR analysis of GO and Gb-rGO}

The FTIR spectrum of GO in Figure 4 (upper) shows the presence of $\mathrm{O}-\mathrm{H}$ stretching at $3,440 \mathrm{~cm}^{-1}$, carboxyl $\mathrm{C}=\mathrm{O}$ and $\mathrm{C}-\mathrm{O}$ stretching at $1,740 \mathrm{~cm}^{-1}$ and $1,390 \mathrm{~cm}^{-1}$, respectively, aromatic $\mathrm{C}=\mathrm{C}\left(1,620 \mathrm{~cm}^{-1}\right)$, and alkoxy $\left(1,076 \mathrm{~cm}^{-1}\right)$ indicating the existence of oxygen containing functional groups on the GO. ${ }^{38,53}$ The substitution of hydroxyl groups on the

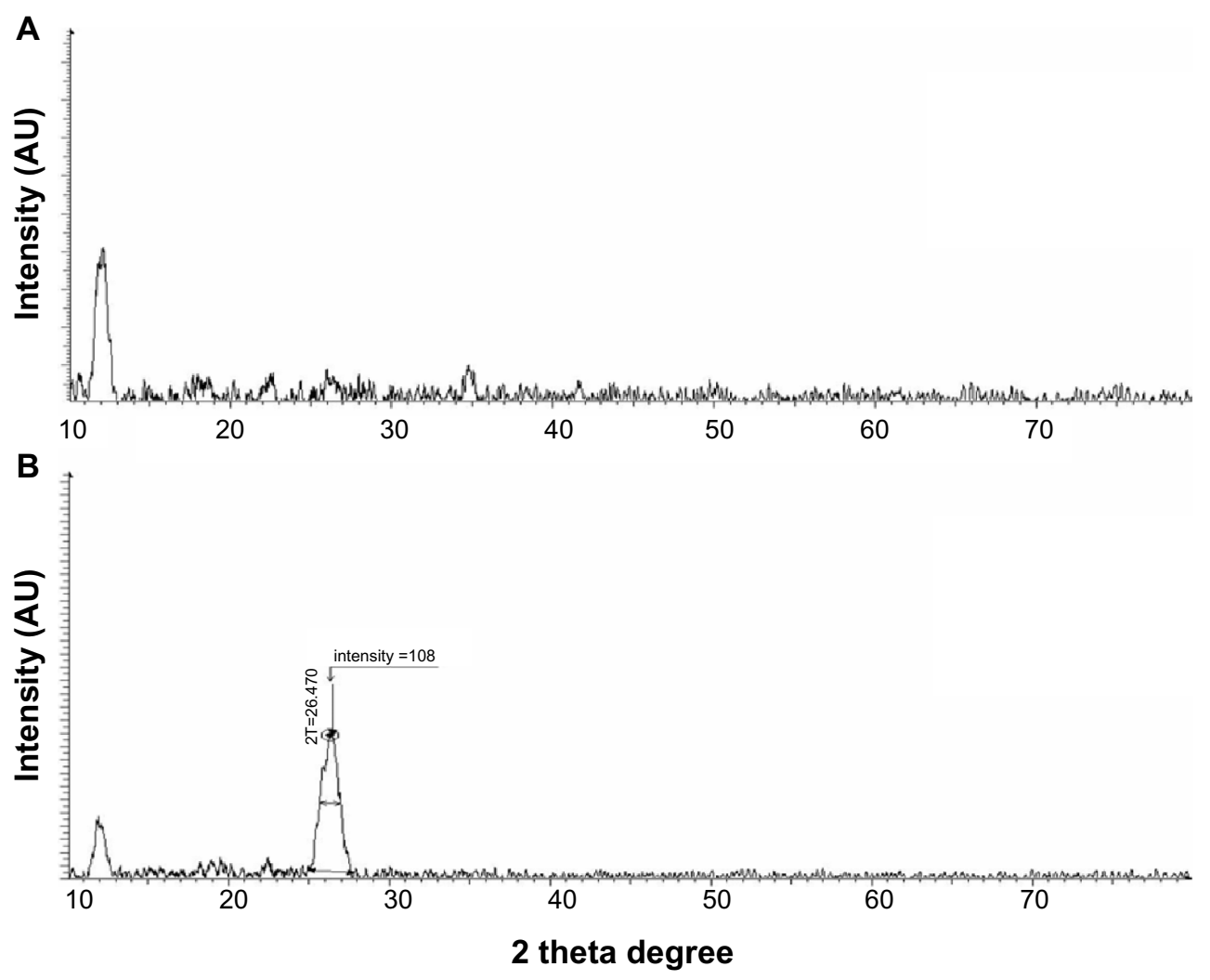

Figure 3 X-ray diffraction pattern of graphene oxide (A) and Ginkgo biloba extract-reduced graphene oxide (B). Abbreviation: $\mathrm{AU}$, arbitrary unit. 


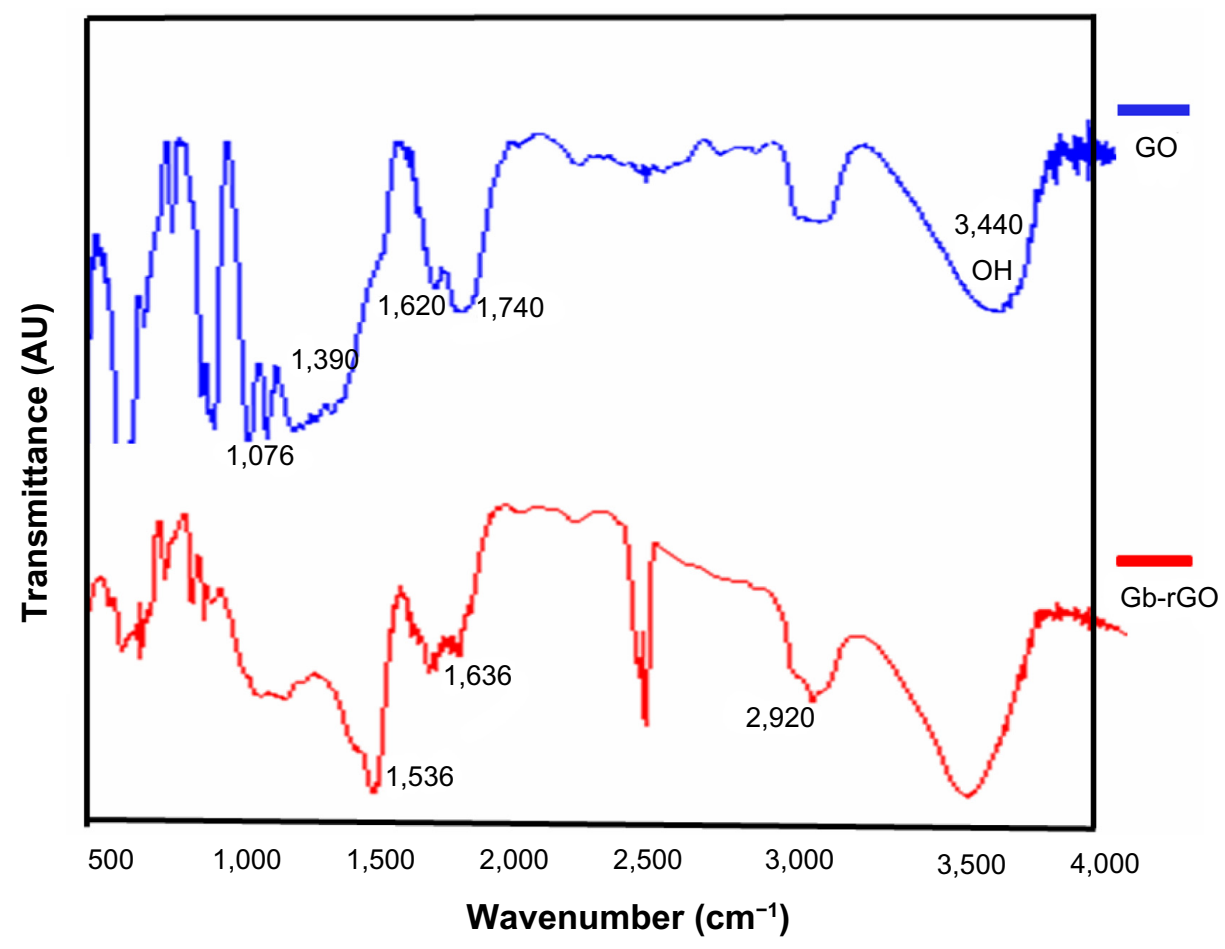

Figure 4 Fourier-transform infrared spectra of graphene oxide (GO) and Ginkgo biloba extract-reduced GO (Gb-rGO).

Abbreviation: $\mathrm{AU}$, arbitrary unit.

GO surface by carboxyl groups was confirmed by the $\mathrm{CH}_{2}-$ stretching vibration at 2,920 $\mathrm{cm}^{-1}$ (Figure 4, lower spectrum). As for the Gb-rGO (lower spectrum), the new band at 1,536 and $1,636 \mathrm{~cm}^{-1}$ corresponds to amide I and amide II, whereas the carboxyl $\mathrm{C}=\mathrm{O}$ stretching of $\mathrm{GO}$ at $1,740 \mathrm{~cm}^{-1}$ disappeared, indicating that $\mathrm{GbE}$ samples could bind to the surface of GO. These observations confirmed that most oxygen functionalities in the GO were removed. ${ }^{54}$ The FTIR spectrum of the Gb-rGO indicates a significant reduction of the intensity of all oxygen-containing moieties, suggesting efficient conversion of GO to graphene by GbE.

\section{Size-distribution analysis of GO and Gb-rGO}

Characterization of the dissolved materials is necessary for particular applications using valuable methods, such as dynamic light scattering (DLS) ${ }^{55}$ DLS theory is a wellestablished technique for measuring round-particle size over a size range from a few nanometers to a few microns. ${ }^{9}$ DLS was employed to measure the approximate size of GO and Gb-rGO samples. As shown in Figure 5A and B, it is clear that the particle sizes of the GO and Gb-rGO were $900 \pm 20 \mathrm{~nm}$ and $1400 \pm 40 \mathrm{~nm}$, respectively. It can be concluded that the particle size of Gb-rGO was increased after reduction. Several studies suggested that the various sizes of reduced GO depend on the type of reducing agent used in the reduction process. Recently, Lammel et al $^{56}$ observed that the average hydrodynamic diameters of GO and carboxyl graphene nanoplatelets were 385 and 1,110 nm, respectively. Stankovich et $\mathrm{al}^{25}$ reported that functionalized graphene nanoplates treated with isocyanate produce a DLS peak of $560 \pm 60 \mathrm{~nm}$. Liu et $\mathrm{al}^{44}$ characterized aqueous dispersions of $\mathrm{Gt}, \mathrm{GtO}, \mathrm{GO}$, and rGO using DLS, and the nominal effective diameters of the particles in $\mathrm{Gt}, \mathrm{GtO}, \mathrm{GO}$, and $\mathrm{rGO}$ dispersions were 5,250, 4,420, 560, and 2,930 nm, respectively. Pseudomonas aeruginosa- and Bacillus marisflavi-reduced GO show $2,600 \mathrm{~nm}$ and 3,800 $\mu \mathrm{m}$, respectively. ${ }^{37,38}$ It is reasonable to conclude that the reducing agent from the leaf extract plays an important role in increasing the size of the as-prepared Gb-rGO.

\section{Raman spectra of GO and Gb-rGO}

Raman spectroscopy is a powerful nondestructive tool to characterize carbonaceous materials, particularly to see the difference between ordered and disordered crystal structures of carbon..$^{57}$ In our study, Raman spectra were used to analyze significant structural changes occurring during the reduction processing from GO to $\mathrm{rGO}$. In Raman spectra, the typical features of carbon showed that the $G$ line was around $1,582 \mathrm{~cm}^{-1}$ and the $D$ line around $1,350 \mathrm{~cm}^{-1}$. The $G$ line is usually assigned to the $E_{2 g}$ phonon of $\mathrm{C} s p^{2}$ atoms, while the $D$ line is a breathing mode of $\kappa$-point phonons 
A Z-average: $900 \mathrm{~nm}$

PDI: 0.141

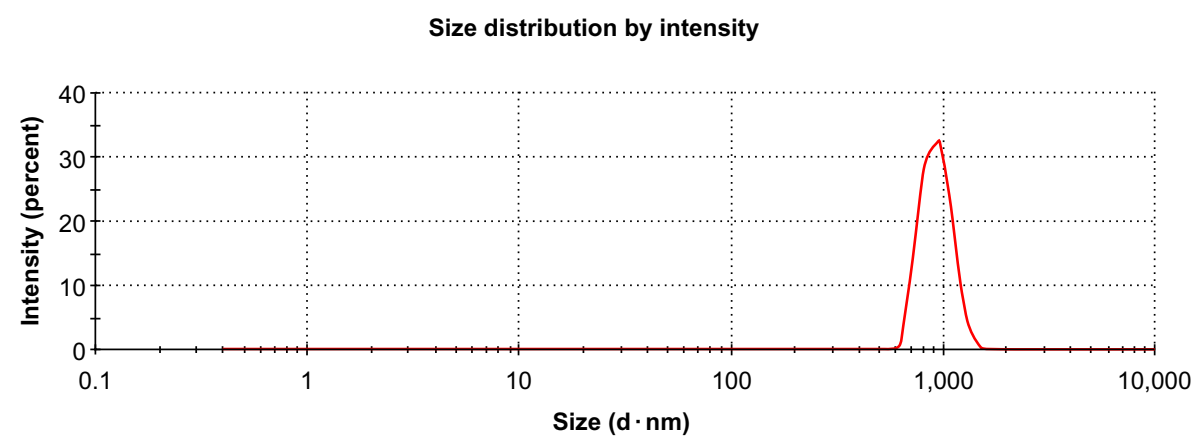

B Z-average: 1,400 nm

PDI: 0.235

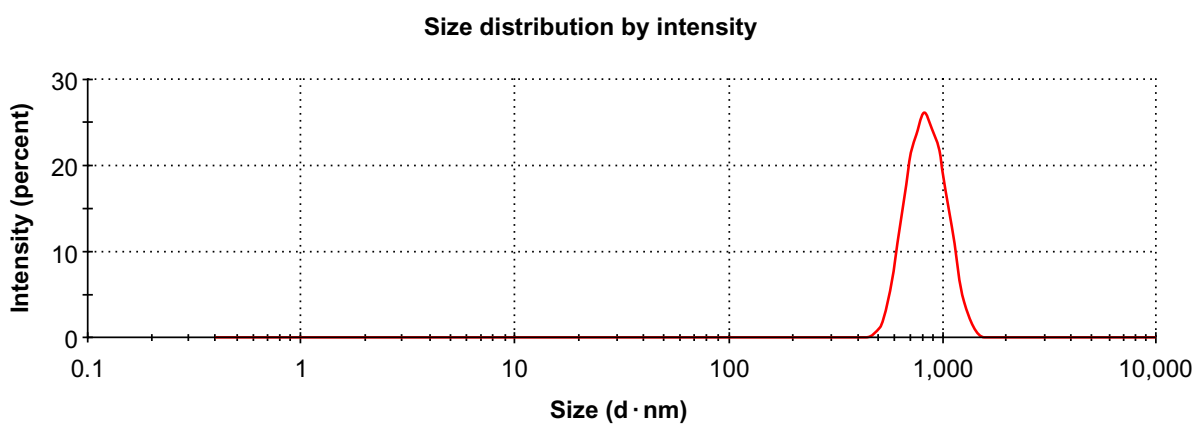

Figure 5 Hydrodynamic size distribution of graphene oxide (A) and Ginkgo biloba extract-reduced graphene oxide (B).

Abbreviations: PDI, polydispersity index; Z, size average.

of $A_{1 g}$ symmetry. ${ }^{58,59}$ In the Raman spectrum of GO, the $G$ band is broadened and shifted to $1,599 \mathrm{~cm}^{-1}$, whereas the $D$-band peak shows at $1,343 \mathrm{~cm}^{-1}$ (Figure 6A), which is prominent, indicating the reduction in size of the in-plane $s p^{2}$ domains, possibly due to the extensive oxidation. The Raman spectrum of the Gb-rGO also contains both $G$ and $D$ bands at 1,603 and $1,355 \mathrm{~cm}^{-1}$, respectively (Figure 6B). Remarkably, the Raman spectrum of Gb-rGO shows a higher intensity ratio (2.0) than GO (1.6). Stankovich et $\mathrm{al}^{25}$ suggested a decrease in the average size of the $s p^{2}$ domains upon reduction of the exfoliated GO. Variations in the relative intensities of the $G$ peak and $D$ peak in the Raman spectra of GO during reduction usually indicate a change in the electronic conjugation state. This change suggests an increase in the number of $s p^{2}$ domains following reduction of GO. ${ }^{25}$ The results of the Raman spectroscopy analyses described here agree with those of previous studies that used the sulfur-containing amino acid L-cysteine to reduce GO to graphene, ${ }^{49}$ or those that developed a green and facile approach for the synthesis of graphene nanosheets using reducing sugars. ${ }^{14,28}$ Our findings are in significant agreement with earlier observations using various biological molecules such as wild carrot root, ${ }^{32}$ Baker's yeast, ${ }^{33}$ and bacterial biomass. ${ }^{35,37}$ In comparison to other biological reducing agents, GbE can be obtained from easily available waste plant products.

\section{Surface morphology of GO and Gb-rGO}

GO sheets were prepared from natural Gt flakes using the methods of Hummers and Offeman. ${ }^{60}$ These sheets had good solubility in water because of their numerous oxygencontaining functional groups. ${ }^{61}$ In general, Gt appears to be piled up in thick cakes, while GO is exfoliated into thin large flakes with wavy wrinkles. ${ }^{61}$ The SEM images revealed that the GO material consisted of individual sheets closely associated with each other, with a silky and leaf-like structure (Figure 7A), whereas Gb-rGO sheets exhibited thin layers of nanosheets and were mainly comprised of larger, wavy forms (Figure 7B). Functionalized graphene nanosheets are mainly wrinkled flakes that are similar to GO, but for graphene nanosheets functionalized with long chains and polymers, the surfaces are coarse and hairy, and the edges of the flakes are blurry. ${ }^{61}$ At higher concentrations, the surfaces of GO sheets have a soft-carpet-like morphology, which 
A

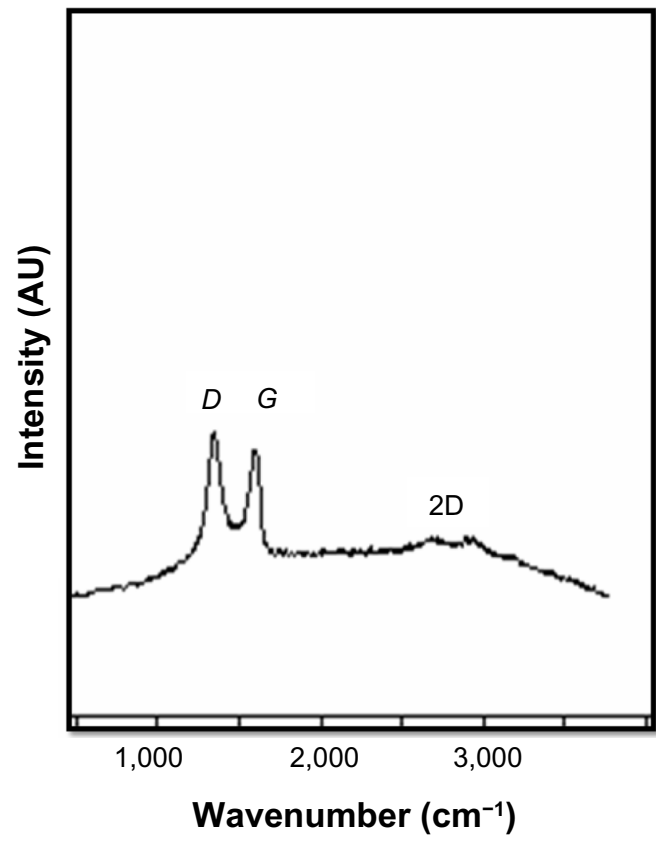

B

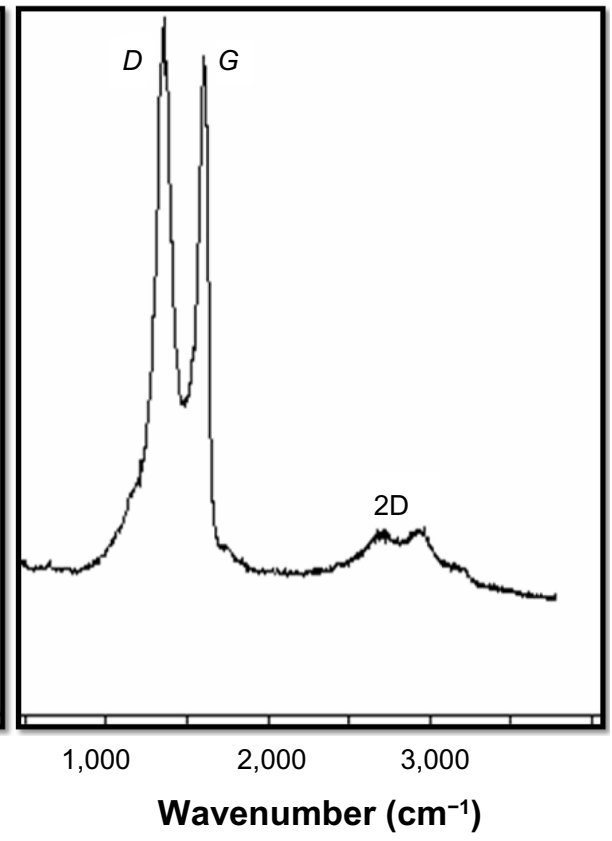

Figure 6 Raman spectra of graphene oxide (A) and Ginkgo biloba extract-reduced graphene oxide (B).

Abbreviations: $\mathrm{AU}$, arbitrary unit; $2 \mathrm{D}$, two-dimensional; $D, D$ band; $G, G$ band.

A

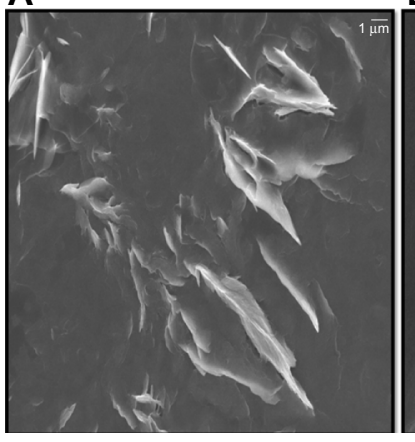

B

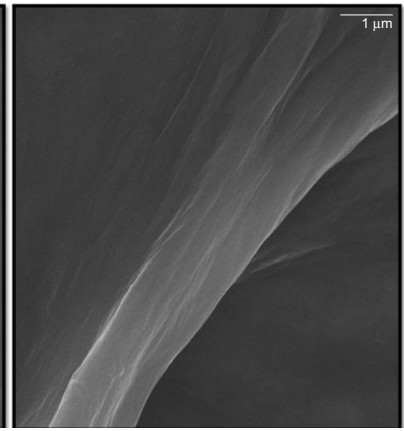

Figure 7 Scanning electron microscopy images of graphene oxide (A) and Ginkgo biloba extract-reduced graphene oxide (B).

may be due to the presence of residual $\mathrm{H}_{2} \mathrm{O}$ molecules and hydroxyl or carboxyl groups attached to $\mathrm{GO} .{ }^{62}$ Furthermore, individual GO sheets can be stacked layer by layer. The SEM images of Gb-rGO samples resembled transparent and rippled silk waves.

\section{Surface and height profile of GO and Gb-rGO by AFM}

AFM is an important technique for evaluating surface morphology and properties. ${ }^{61} \mathrm{AFM}$ can also be used to measure the surface and height profiles of individual graphene sheets. Therefore, AFM images are regarded as the most important indication of the successful functionalization of graphene. ${ }^{61,63-65}$ Figure 8A and B shows typical AFM images of $\mathrm{GO}$ and $\mathrm{Gb}-\mathrm{rGO}$ dispersions in water, after their deposition on a freshly cleaned glass surface. The average thickness of as-prepared Gb-rGO, measured from the height profile of the AFM image, is about $57.48 \mathrm{~nm}$. Compared with the well-exfoliated GO sheets with a thickness of about $36.68 \mathrm{~nm}, \mathrm{~Gb}-\mathrm{rGO}$ was thicker than GO. Stankovich et $\mathrm{a}^{25}$ reported that GO sheets are "thicker" due to the presence of covalently bound oxygen and the displacement of the $s p^{3}$ hybridized carbon atoms slightly above and below the original graphene plane. From our results, it is suggested that the reducing agent plays an important role in increasing the thickness of the as prepared Gb-rGO, through removing most of the oxygen-containing functional groups in GO. $\mathrm{Su}$ et $\mathrm{a}{ }^{166}$ demonstrated that dispersed molecules with large aromatic structures and extra negative charges are noncovalently immobilized on the basal plane of graphene sheets via strong interactions.

\section{The effect of Gb-rGO on cell viability}

Cell viability is one of the most important factors to evaluate the biocompatibility of graphene materials. To estimate the biocompatibility of GO and Gb-rGO, the cells were treated with various concentrations of $\mathrm{GO}$ and $\mathrm{Gb}-\mathrm{rGO}$ $(0-100 \mu \mathrm{g} / \mathrm{mL})$ for 24 hours. At higher GO concentrations (50-100 $\mu \mathrm{g} / \mathrm{mL})$, viability loss was observed and was significantly different from control samples, whereas 


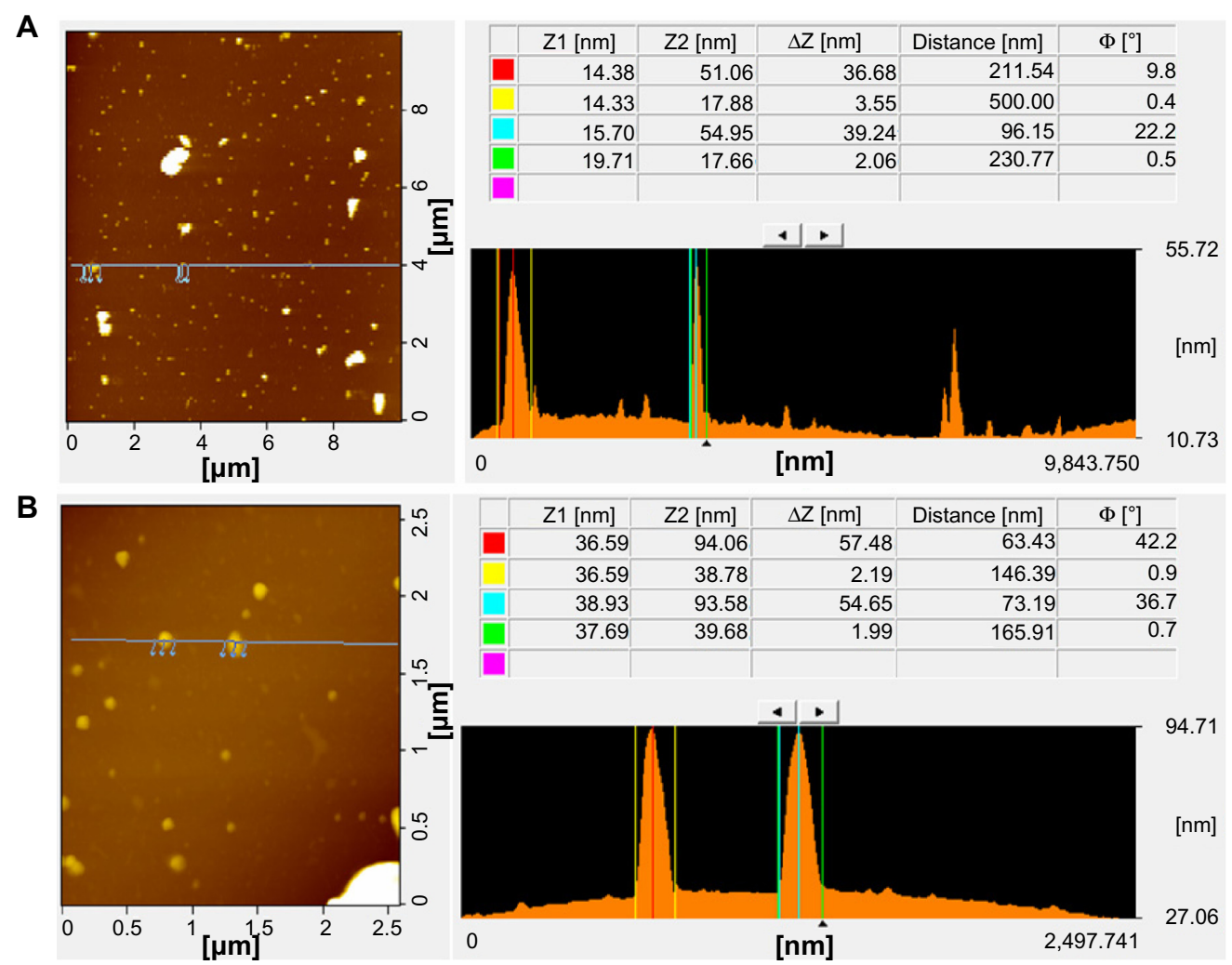

Figure 8 Atomic force microscopy images of graphene oxide (A) and Ginkgo biloba extract-reduced graphene oxide (B).

Gb-rGO-treated cells showed no significant inhibitory effect on cell viability (Figure 9). These results indicated that the viability of cells was not affected by Gb-rGO at any of the working concentrations. Chang et a ${ }^{67}$ undertook a comprehensive study on the toxicity of GO by examining various parameters, such as morphology, viability, mortality, and membrane integrity of A549 cells, and finally suggested that GO does not enter A549 cells and

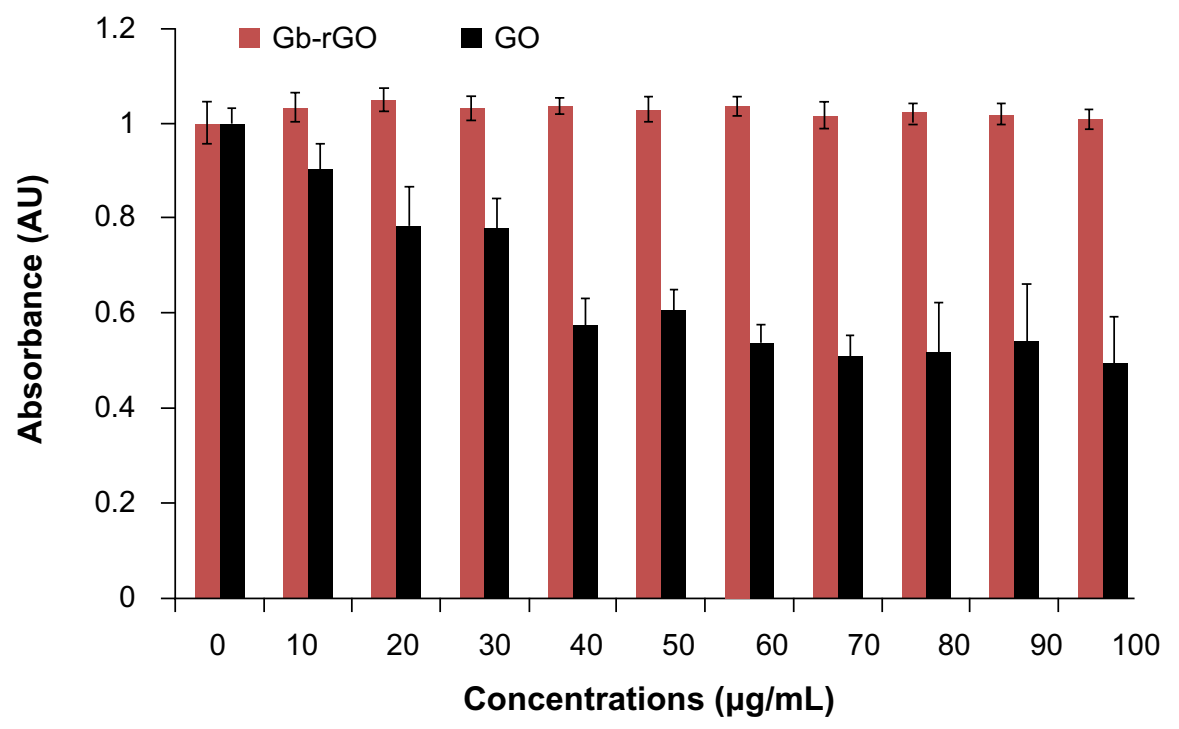

Figure 9 Effect of graphene oxide (GO) and Ginkgo biloba extract-reduced GO (Gb-rGO) on cell viability of MDA-MB-23I human cancer cells. Cell viability of MDA-MB231 cells was determined by water-soluble tetrazolium 8 assay after 24-hour exposure to different concentrations of GO or Gb-rGO. The results represent the means of three separate experiments, and error bars represent the standard error of the mean. GO-treated groups showed statistically significant differences from the control group by Student's $t$-test $(P<0.05)$.

Abbreviation: $\mathrm{AU}$, arbitrary unit. 
has no obvious cytotoxicity, but that GO can cause dosedependent oxidative stress in cells and induce a slight loss of cell viability at higher concentrations. Chen et $\mathrm{al}^{68}$ investigated the biocompatibility of graphene films using a mouse fibroblast cell line (L-929), and the results showed that the cells adhered and proliferated on graphene film well and that graphene film is biocompatible. Agarwal et $\mathrm{al}^{16}$ reported that $\mathrm{rGO}$ is more biocompatible than single-wall carbon nanotubes (CNTs), using different cell lines: neuroendocrine PC12 cells, oligodendroglia, and osteoblasts. Cells were cultured in parallel on CNTs and rGO films with the same initial seeding density. The proliferation of PC12 cells on the two types of substrates was monitored over 5 days after seeding. The cells proliferated well on rGO, whereas their proliferation was largely inhibited on NTs. Biris et $\mathrm{al}^{69}$ demonstrated that osteoblast cells (MC3T3-E1) have a high ability to grow on graphene film. Zhang et $\mathrm{al}^{70}$ also reported that fewlayer graphene increased intracellular generation of ROS and induced mitochondrial injury in neuronal cells after 4 and 24 hours at a dose of $10 \mu \mathrm{g} / \mathrm{mL}$. Lu et $\mathrm{al}^{71}$ suggested that surface modification of graphene plays an important role in reducing the toxicity of rGO and carboxylated graphene.
A
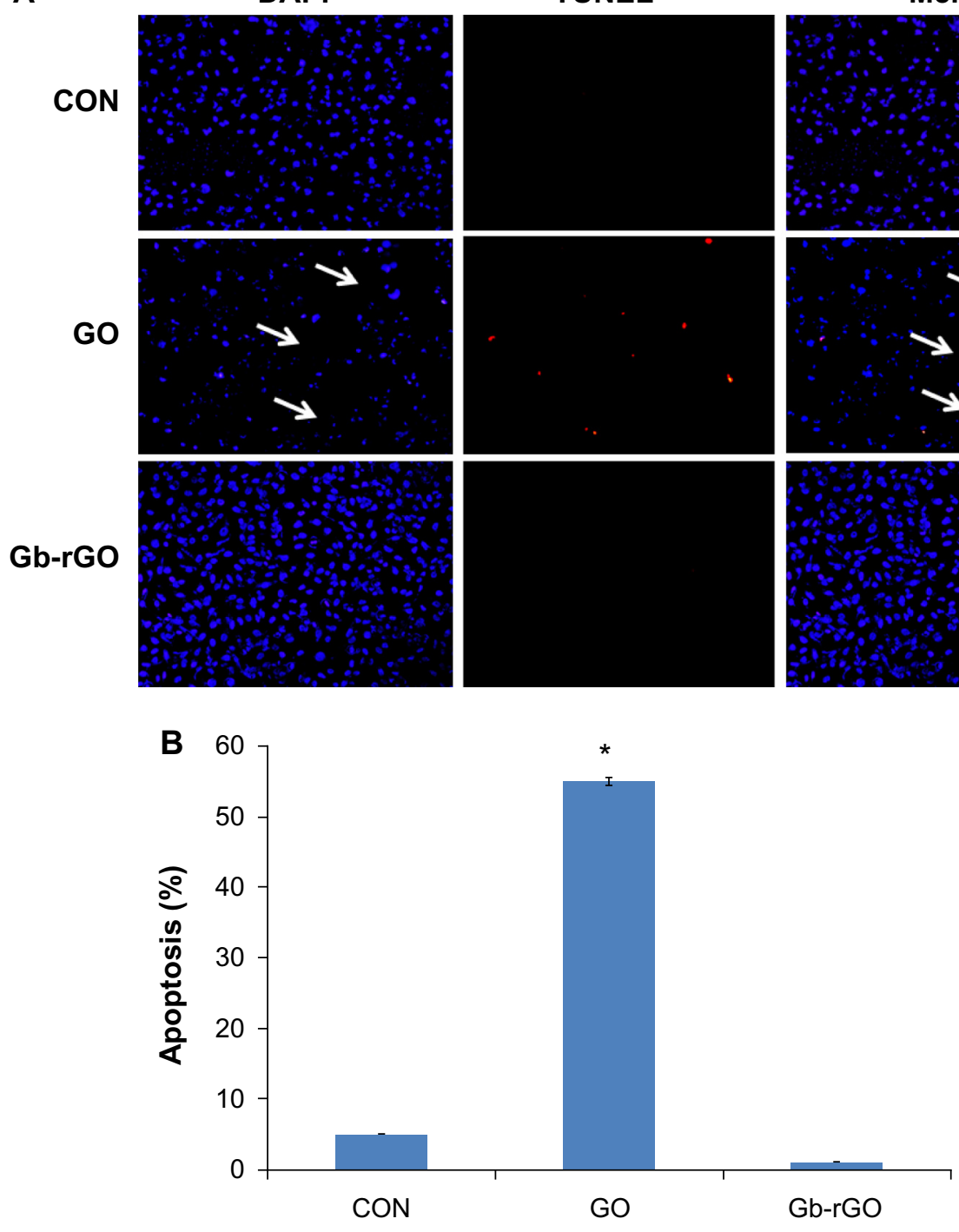

TUNEL
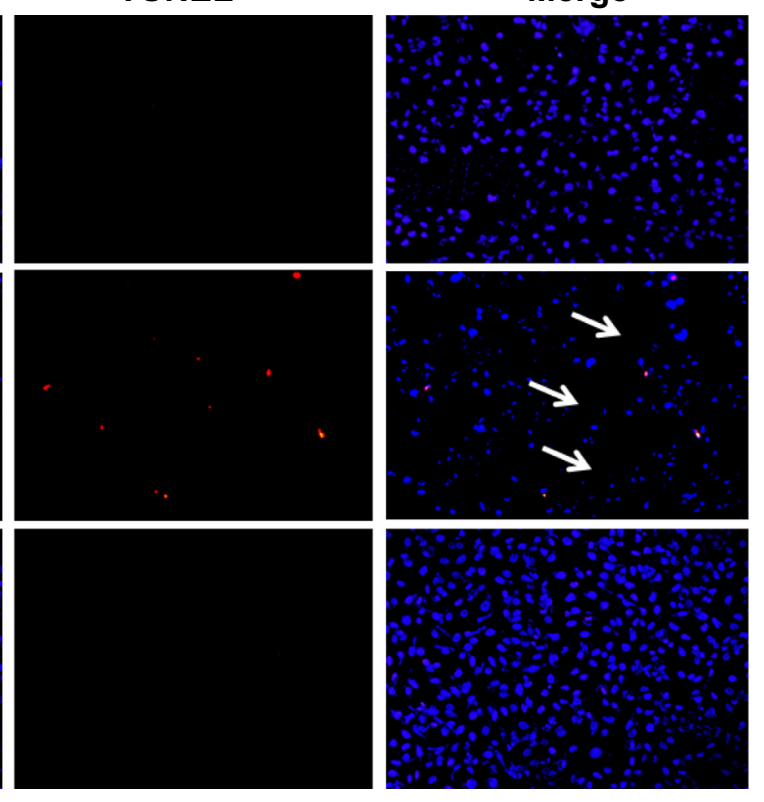

Merge

. \\ .}

(n) 


\section{Cytocompatibility of Gb-rGO}

Cytocompatibility depends on the dispersant used to stabilize the suspension, the type of materials, and the concentration. ${ }^{53}$ To determine cytocompatibility, the cells were treated with various concentrations of GO and Gb-rGO $(100 \mu \mathrm{g} / \mathrm{mL})$ for 24 hours, and cell death was examined using the TUNEL assay. TUNEL is a rapid method for identification and quantification of the apoptotic cell fraction in cultured cell preparations. ${ }^{72}$ Cell death is characterized by apoptotic morphology, chromatin condensation, membrane blebbing, internucleosome degradation of DNA, and apoptotic body formation. ${ }^{70,73}$ Following treatment with GO and Gb-rGO for 24 hours, the morphological features of apoptosis, condensation of chromatin, and fragmentation of the nucleus were examined. Use of the TUNEL assay further confirmed the induction of apoptosis by GO in cancer cells. As shown in Figure 10A, DNA fragmentation and rate of cell death was increased in cells treated with GO compared to control cells. Control and Gb-rGO-treated cells showed round and homogeneous nuclei, and no TUNEL-positive cells were observed, whereas cells treated with GO displayed condensed and fragmented nuclei in TUNEL-positive cells (Figure 10A). Interestingly, in the Gb-rGO-treated dish, all the cells were attached and appeared healthy. In contrast, GO-treated cells were fewer in number, and most were detached from the dish. The rate of apoptosis increased in GO-treated samples compared to Gb-rGO (Figure 10B). Taken together, all these results suggest that Gb-rGO could be a cytocompatiblefriendly material. In a similar vein, Wojtoniszak et $\mathrm{al}^{53}$ reported that cells exposed to $\mathrm{rGO} /$ polyethylene glycol (PEG) suspension at concentrations between $3.125 \mu \mathrm{g} / \mathrm{mL}$ and $25 \mu \mathrm{g} / \mathrm{mL}$ showed relatively higher cytocompatibility than GO-treated cells. Yang et $\mathrm{a}^{13}$ reported on the pharmacokinetics and biodistribution of graphene functionalized with PEG, examining toxicity in mice, and the results suggested that graphene/PEG does not induce appreciable toxicity at an administered dose of $20 \mathrm{mg} / \mathrm{kg}$ for 3 months. Feng et a ${ }^{74}$ reported that at high concentrations, polyethyleneimine (PEI) graphene complexes showed slightly higher cell viability in human epithelial carcinoma compared to GO, possibly due to the improved stability of GO-PEI in the physiological environment. Sayes et $\mathrm{al}^{75}$ suggested that the toxicity of CNTs depends on the degree of functionalization, which is due to the carboxylation of CNTs making oxygen atoms abundant and decreasing toxicity.

\section{Impact of Gb-rGO on ALP activity}

Biocompatibility and nontoxicity are essential parameters for potential applications of any kind of nanomaterial in biomedical applications. ALP is a membrane enzyme that is involved in the mineralization of skeletal tissues, and the activity of this enzyme was used as a marker of osteoblastic differentiation. ${ }^{76}$ Biological responses of GO and Gb-rGO were preliminarily examined using the cell-viability assay, the results of which

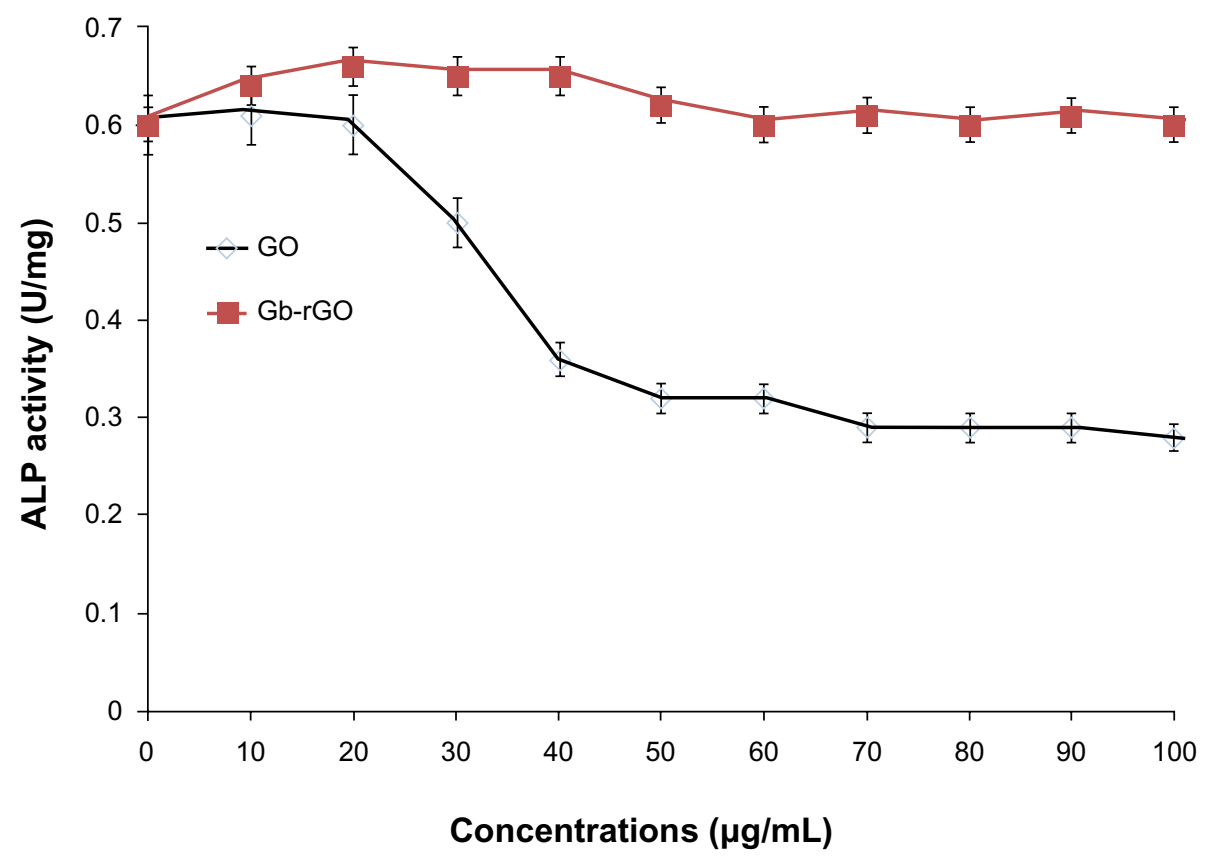

Figure II The effect of graphene oxide (GO) and Ginkgo biloba extract-reduced GO (Gb-rGO) on alkaline phosphatase (ALP) activity. MDA-MB-23 I cells were treated with various concentrations of GO and Gb-rGO for 5 days. The results represent the means of three separate experiments, and error bars represent the standard error of the mean. GO-treated groups showed statistically significant differences from the control group by Student's $t$-test $(P<0.05)$. 
showed that Gb-rGO was neither enhanced nor proliferation of MDA-MB-231 human breast cancer cells inhibited. ALP results showed that cells treated with GO showed significantly lower ALP activity than Gb-rGO treated cells and untreated cells (Figure 11), which indicates that Gb-rGO was significantly biocompatible. Liu et $\mathrm{al}^{77}$ investigated the effect of pure hydroxyapatite (HA) and HA-rGO composites on ALP activity, and concluded that HA-rGO-treated cells showed higher ALP than untreated cells. Recently, Liu et al and Kalbacova et al ${ }^{17,78}$ reported that single-walled CNTs show better adherence and proliferation of human osteoblasts and mesenchymal stromal cells on them than silica. MG63 cells cultured with lower concentrations of nanographene platelets showed higher ALP expression when compared to those without nanographene platelets. ${ }^{79} \mathrm{Li}$ et $\mathrm{l}^{80}$ demonstrated that MG-63 cells cultured with GO-HA and CS-GO-HA composites showed higher ALP activities than the control groups.

\section{Conclusion}

Graphene nanomaterials are being used in increasingly large quantities for many applications in daily life, due to their novel characteristics, such as thermal, electrical, mechanical, and biological properties. Here, we developed an environmentally friendly approach for the reduction of $\mathrm{GO}$ by using $\mathrm{GbE}$ as a reducing and stabilizing agent. This is the first report about the use of G. biloba as bioreductant for the preparation of graphene. This biological reduction method is simple, cost-effective, and avoids the use of any toxic reagents, and also it offers another route to the production of graphene. Further, we assessed the cytocompatibility effect of biologically synthesized graphene in human cancer cells using various assays, such as cell viability, TUNEL, and ALP activity in human breast cancer cells. The results showed that the parent-material GO exhibited dose-dependent toxicity in cancer cells, whereas Gb-rGO showed significant cytocompatibility even at a high concentration of $100 \mu \mathrm{g} / \mathrm{mL}$. Biologically synthesized graphene could be a favorable nanoplatform and the best candidate for biomedical applications, such as tissue engineering, imaging, and drug delivery.

\section{Acknowledgments}

This paper was supported by the SMART Research Professor Program of Konkuk University. Dr Sangiliyandi Gurunathan was supported by a Konkuk University SMART full-time professorship. This work was supported by Woo Jang-Choon project (PJ007849) and next generation of Biogreen 21 (PJ009107) from the Rural Development Administration (RDA), Republic of Korea.

\section{Disclosure}

The authors report no conflicts of interest in this work.

\section{References}

1. Novoselov KS, Geim AK, Morozov SV, et al. Electric field effect in atomically thin carbon films. Science. 2004;306(5696):666-669.

2. Wang Y, Shi Z, Yin J. Facile synthesis of soluble graphene via a green reduction of graphene oxide in tea solution and its biocomposites. ACS Appl Mater Interfaces. 2011;3(4):1127-1133.

3. Geim KA, Novoselov KS. The rise of graphene. Nat Mater. 2007;6(3): 183-191.

4. Rao CNR, Sood AK, Subrahmanyam KS, Govindaraj A. Graphene: the new two-dimensional nanomaterial. Angew Chem Int Ed Engl. 2009;48(42):7752-7777.

5. Allen MJ, Tung VC, Kaner RB. Honeycomb carbon: a review of graphene. Chem Rev. 2010;110:132-145.

6. Shao Y, Wang J, Wu H, Liu J, Aksay IA, Lin Y. Graphene based electrochemical sensors and biosensors. Electroanalysis. 2010;22(10): 1027-1036.

7. Akhavan O, Ghaderi E, Rahighi R. Toward single-DNA electrochemical biosensing by graphene nanowalls. ACS Nano. 2012;6(4): 2904-2916.

8. Mohanty N, Berry V. Graphene-based single-bacterium resolution bio device and DNA transistor: interfacing graphene derivatives with nanoscale and microscale biocomponents. Nano Lett. 2000;8(12): 4469-4476.

9. $\mathrm{Hu} \mathrm{W}$, Peng $\mathrm{C}$, Luo W, et al. Graphene-based antibacterial paper. $A C S$ Nano. 2010;4(7):4317-4323.

10. Akhavan O, Ghaderi E. Toxicity of graphene and graphene oxide nanowalls against bacteria. ACS Nano. 2010;4(10):5731-5736.

11. Gurunathan S, Han JW, Eppakayala V, Kim JH. Oxidative stress-mediated antibacterial activity of graphene oxide and reduced graphene oxide in Pseudomonas aeruginosa. Int J Nanomedicine. 2012;7:5901-5914.

12. Akhavan O, Choobtashani M, Ghaderi E. Protein degradation and RNA efflux of viruses photocatalyzed by graphene-tungsten oxide composite under visible light irradiation. J Phys Chem C. 2012;116(17): 9653-9659.

13. Yang K, Zhang S, Zhang G, Sun X, Lee ST, Liu Z. Graphene in mice: ultrahigh in vivo tumor uptake and efficient photothermal therapy. Nano Lett. 2010;10(9):3318-3323.

14. Akhavan O, Ghaderi E, Aghayee S, Fereydooni Y, Talebi A. The use of a glucose-reduced graphene oxide suspension for photothermal cancer therapy. J Mater Chem. 2012;22:13773-13781.

15. Zhang X, Yin J, Peng C, et al. Distribution and biocompatibility studies of graphene oxide in mice after intravenous administration. Carbon. 2011;49(3):986-995.

16. Agarwal S, Zhou X, Ye F, et al. Interfacing live cells with nanocarbon substrates. Langmuir. 2010;26(4):2244-2247.

17. Park S, Mohanty N, Suk JW, et al. Biocompatible, robust free-standing paper composed of a TWEEN/graphene composite. Adv Mater. 2010; 22(15):1736-1740.

18. Lee WC, Lim CH, Shi H, et al. Origin of enhanced stem cell growth and differentiation on graphene and graphene oxide. ACS Nano. 2011;5(9):7334-7341.

19. Nayak TR, Andersen H, Makam VS, et al. Graphene for controlled and accelerated osteogenic differentiation of human mesenchymal stem cells. ACS Nano. 2011;5(6):4670-4678.

20. Chen GY, Hwang SM, Su HJ, et al. Defective antiviral responses of induced pluripotent stem cells to baculoviral vector transduction. J Virol. 2012;86(15):8041-8049.

21. Gurunathan S, Han JW, Eppakayala V, Kim JH. Green synthesis of graphene and its cytotoxic effects in human breast cancer cells. Int $J$ Nanomedicine. 2013;8:1015-1027.

22. Sanchez VC, Jachak A, Hurt RH, Kane AB. Biological interactions of graphene-family nanomaterials: an interdisciplinary review. Chem Res Toxicol. 2011;25(1):15-34. 
23. Fernández-Merino MJ, Guardia L, Paredes JL, et al. Vitamin C is an ideal substitute for hydrazine in the reduction of graphene oxide suspensions. J Phys Chem C. 2010;114(14):6426-6432.

24. Stankovich S, Piner RD, Chen X, Wu N, Nguyen ST, Ruoff RS. Aqueous dispersions of graphitic nanoplatelets via the reduction of exfoliated graphite oxide in the presence of poly(sodium 4-styrenesulfonate). J Mater Chem. 2006;16:155-158.

25. Stankovich S, Dikin DA, Piner RD, et al. Synthesis of graphene-based nanosheets via chemical reduction of exfoliated graphite oxide. Carbon. 2007;45(7):1558-1565.

26. Cote LJ, Silva RC, Huang J. Flash reduction and patterning of graphite oxide and its polymer composite. J Am Chem Soc. 2009;131(31): 11027-11032.

27. Zhou M, Zhai Y, Dong S. Electrochemical sensing and biosensing platform based on chemically reduced graphene oxide. Anal Chem. 2009;81(14):5603-5613.

28. Zhu C, Guo S, Fang Y, Dong S. Reducing sugar: new functional molecules for the green synthesis of graphene nanosheets. ACS Nano. 2010;4(4):2429-2437.

29. Hass J, de Heer WA, Conrad EH. The growth and morphology of epitaxial multilayer graphene. J Phys Condens Matter. 2008;20(32):323202.

30. Akhavan O, Ghaderi EJ. Photocatalytic reduction of graphene oxide nanosheets on $\mathrm{TiO}_{2}$ thin film for photoinactivation of bacteria in solar light irradiation. J Phys Chem C. 2009;113(47):20214-20220.

31. Akhavan O, Abdolahad M, Esfandiar A, Mohatashamifar M. Photodegradation of graphene oxide sheets by $\mathrm{TiO}_{2}$ nanoparticles after a photocatalytic reduction. J Phys Chem C. 2010;114(30): 12955-12959.

32. Kuila T, Bose B, Khanra P, Mishra AK, Kim NH, Lee JH. A green approach for the reduction of graphene oxide by wild carrot root. Carbon. 2012;50(3)914-921.

33. Khanra P, Kuila T, Kim NH, Bae SH, Yu DS, Lee JH. Simultaneous bio-functionalization and reduction of graphene oxide by baker's yeast. Chem Eng J. 2012;183:526-533.

34. Akhavan O, Ghaderi E. Escherichia coli bacteria reduce graphene oxide to bactericidal graphene in a self-limiting manner. Carbon. 2012;50(5):1853-1860.

35. Gurunathan S, Han JW, Eppakayala V, Kim JH. Microbial reduction of graphene oxide by Escherichia coli: a green chemistry approach. Colloids Surf B Biointerfaces. 2013;102:772-777.

36. Gurunathan S, Han JW, Eppakayala V, Kim JH. An environmentally friendly approach to the reduction of graphene oxide by Escherichia fergusoni. J Nanosci Nanotechnol. 2013;13(3):2091-2098.

37. Gurunathan S, Han JW, Dayem AA, Eppakayala V, Kim JH. Biocompatibility of microbially reduced graphene oxide in primary mouse embryonic fibroblast cells. Colloids Surf B Biointerfaces. 2013;105:58-66.

38. Gurunathan S, Han JW, Kim JH. Humanin: a novel functional molecule for the green synthesis of graphene. Colloids Surf B Biointerfaces. 2013;111:376-383.

39. Thakur S, Karak N. Green reduction of graphene oxide by aqueous phytoextracts. Carbon. 2012;50(14):5331-5339.

40. Park Y, Hong YN, Weyers A, Kim YS, Linhardt RJ. Polysaccharides and phytochemicals: a natural reservoir for the green synthesis of gold and silver nanoparticles. IET Nanobiotechnol. 2011;5(3):69-78.

41. Iravani S. Green synthesis of metal nanoparticles using plants. Green Chem. 2011;13(10):2638-2650.

42. Esfandiar A, Akhavan O, Irajizad A. Melatonin as a powerful bioantioxidant for reduction of graphene oxide. J Mater Chem. 2011;21: 10907-10914.

43. Liao KH, Lin YS, Macosko CW, Haynes CL. Cytotoxicity of graphene oxide and graphene in human erythrocytes and skin fibroblasts. ACS Appl Mater Interfaces. 2011;3(7):2607-2615.

44. Liu S, Zeng TH, Hofmann M, et al. Antibacterial activity of graphite, graphite oxide, graphene oxide, and reduced graphene oxide: membrane and oxidative stress. ACS Nano. 2011;5(9):6971-6980.
45. Wang Y, Shi Z, Yin J. Facile synthesis of soluble graphene via a green reduction of graphene oxide in tea solution and its biocomposites. ACS Appl Mater. Interfaces. 2011;3(4):1127-1133.

46. Li D, Müller MB, Gilje S, Kaner RB, Wallace GG. Processable aqueous dispersions of graphene nanosheets. Nat Nanotechnol. 2008;3(2):101-105.

47. Pham TA, Choi BC, Jeong YT. Facile covalent immobilization of cadmium sulfide quantum dots on graphene oxide nanosheets: preparation, characterization, and optical properties. Nanotechnology. 2010;21(46):465603.

48. Wang J, Zhou T, Deng H, et al. An environmentally friendly and fast approach to prepare reduced graphite oxide with water and organic solvents solubility. Colloids Surf B Biointerfaces. 2013;101: 171-176.

49. Chen D, Li L, Guo L. An environment-friendly preparation of reduced graphene oxide nanosheets via amino acid. Nanotechnology. 2011;22(32):325601

50. Wu Q, Xu YX, Yao ZY, Liu AR, Shi GQ. Supercapacitors based on flexible graphene/polyaniline nanofiber composite films. ACS Nano. 2010;4(4):1963-1970.

51. Shen J, Hu Y, Shi M, et al. Fast and facile preparation of graphene oxide and reduced graphene oxide nanoplatelets. Chem Mater. 2009;21(15):3514-3520.

52. Park S, An J, Jung I, et al. Colloidal suspensions of highly reduced graphene oxide in a wide variety of organic solvents. Nano Lett. 2009;9(4): 1593-1597.

53. Wojtoniszak M, Chen X, Kalenczuk RJ, et al. Synthesis, dispersion, and cytocompatibility of graphene oxide and reduced graphene oxide. Colloids Surf B Biointerfaces. 2012;89:79-85.

54. Gao J, Liu F, Liu Y, Ma N, Wang Z, Zhang X. Environment-friendly method to produce graphene that employs vitamin $\mathrm{C}$ and amino acid. Chem Mater. 2010;22(7):2213-2218.

55. Pénicaud A, Drummond C. Deconstructing graphite: graphenide solutions. Acc Chem Res. 2013;46(1):129-137.

56. Lammel T, Boisseaux P, Fernández-Cruz ML, Navas J. Internalization and cytotoxicity of graphene oxide and carboxyl graphene nanoplatelets in the human hepatocellular carcinoma cell line Hep G2. Part Fibre Toxicol. 2013;10(1):27.

57. Wang G, Yang J, Park J, et al. Facile synthesis and characterization of graphene nanosheets. J Phys Chem C. 2008;112(22):8192-8195.

58. Tuinstra F, Koenig JL. Raman spectrum of graphite. J Chem Phys. 1970;53:1126-1130.

59. Ferrari AC, Robertson J. Interpretation of Raman spectra of disordered and amorphous carbon. Phys Rev B Condens Matter Mater Phys. 2000;61(20):14095-14107.

60. Hummers WS, Offeman RE. Preparation of graphitic oxide. JAm Chem Soc. 1958;80(6):1339-1339.

61. He H, Gao C. General approach to individually dispersed, highly soluble, and conductive graphene nanosheets functionalized by nitrene chemistry. Chem Mater. 2010;22(17):5054-5064.

62. Jeong HK, Lee YP, Lahaye RJ, et al. Evidence of graphitic AB stacking order of graphite oxides. J Am Chem Soc. 2008;130(4):1362-1366.

63. $\mathrm{Xu} \mathrm{Z,} \mathrm{Gao} \mathrm{C.} \mathrm{Aqueous} \mathrm{liquid} \mathrm{crystals} \mathrm{of} \mathrm{graphene} \mathrm{oxide.} \mathrm{ACS} \mathrm{Nano.}$ 2011;5(4):2908-2915.

64. Hu X, Xu Z, Gao C. Multifunctional, supramolecular, continuous artificial nacre fibres. Sci Rep. 2012;2:767.

65. Xu Z, Sun H, Zhao X, Gao C. Ultrastrong fibers assembled from giant graphene oxide sheets. Adv Mater. 2013;25(2):188-193.

66. Su CY, Xu Y, Zhang W, et al. Electrical and spectroscopic characterizations of ultra-large reduced graphene oxide monolayers. Chem Mater. 2009;21(23):5674-5680.

67. Chang Y, Yang ST, Liu JH, et al. In vitro toxicity evaluation of graphene oxide on A549 cells. Toxicol Lett. 2011;200(3):201-210.

68. Chen H, Müller MB, Gilmore KJ, Wallace GG, Li D. Mechanically strong, electrically conductive, and biocompatible graphene paper. $A d v$ Mater. 2008;20(18):3557-3561. 
69. Biris AR, Mahmood M, Lazar MD, et al. Novel multicomponent and biocompatible nanocomposite materials based on few-layer graphenes synthesized on a gold/hydroxyapatite catalytic system with applications in bone regeneration. J Phys Chem C. 2011;115(39): 18967-18976.

70. Zhang Y, Ali SF, Dervishi E, et al. Cytotoxicity effects of graphene and single-wall carbon nanotubes in neural phaeochromocytoma-derived PC12 cells. ACS Nano. 2010;4(6):3181-3186.

71. Lu CH, Zhu CL, Li J, Liu JJ, Chen X, Yang HH. Using graphene to protect DNA from cleavage during cellular delivery. Chem Commun (Camb). 2010;46(18):3116-3118.

72. Negoescu A, Lorimier P, Labat-Moleur F, et al. In situ apoptotic cell labeling by the TUNEL method: improvement and evaluation on cell preparations. J Histochem Cytochem. 1996;44(9):959-968.

73. Zhang Y, Zhou L, Bao YL, et al. Butyrate induces cell apoptosis through activation of JNK MAP kinase pathway in human colon cancer RKO cells. Chem Biol Interact. 2010;185(3):174-181.

74. Feng L, Zhang S, Liu Z. Graphene based gene transfection. Nanoscale. 2011;3(3):1252-1257.
75. Sayes CM, Liang F, Hudson JL, et al. Functionalization density dependence of single-walled carbon nanotubes cytotoxicity in vitro. Toxicol Lett. 2006;161(2):135-142.

76. Gotoh Y, Hiraiwa K, Nagayama M. In vitro mineralization of osteoblastic cells derived from human bone. Bone Miner. 1990;8(3):239-250.

77. Liu Y, Huang J, Li H. Synthesis of hydroxyapatite-reduced graphite oxide nanocomposites for biomedical applications: oriented nucleation and epitaxial growth of hydroxyapatite. J Mater Chem B. 2013;1(13): 1826-1834.

78. Kalbacova M, Broz A, Kromka A, Babchenko O, Kalbac M. Controlled oxygen plasma treatment of single-walled carbon nanotube films improves osteoblastic cells attachment and enhances their proliferation. Carbon. 2011;49(9):2926-2934.

79. Zhang X, Li M, Wang YB, et al. Cell response of nanographene platelets to human osteoblast-like MG63 cells. J Biomed Mater Res Part A. Epub April 16, 2013.

80. Li M, Wang Y, Liu Q, et al. In situ synthesis and biocompatibility of nanohydroxyapatite on pristine and chitosan functionalized graphene oxide. J Mater Chem B. 2013;1(4):475-484.
International Journal of Nanomedicine

\section{Publish your work in this journal}

The International Journal of Nanomedicine is an international, peerreviewed journal focusing on the application of nanotechnology in diagnostics, therapeutics, and drug delivery systems throughout the biomedical field. This journal is indexed on PubMed Central,

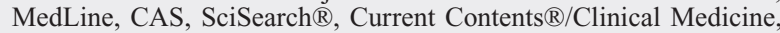

\section{Dovepress}

Journal Citation Reports/Science Edition, EMBase, Scopus and the Elsevier Bibliographic databases. The manuscript management system is completely online and includes a very quick and fair peer-review system, which is all easy to use. Visit http://www.dovepress.com/ testimonials.php to read real quotes from published authors. 